\section{Ciliary neurotrophic factor induces type-2 astrocyte differentiation in culture}

\author{
Simon M. Hughes*†, Laura E. Lillien*, \\ Martin C. Raff*, Hermann Rohrerł \\ \& Michael Sendtner $\ddagger$ \\ * MRC Developmental Neurobiology Programme, \\ Department of Biology, Medawar Building, \\ University College London, London WC1E 6BT, UK \\ $\neq$ Department of Neurochemistry, \\ Max-Planck Institute for Psychiatry, Am Klopferspitz 18a, \\ D-8033 Martinsried, FRG
}

We have been studying a population of bipotential glial progenitor cells in the perinatal rat optic nerve and brain in an attempt to understand how cells choose between alternative fates in the developing mammalian central nervous system (CNS). This cell population gives rise initially to oligodendrocytes and then to type-2 astrocytes ${ }^{1}$, both of which apparently collaborate in sheathing axons in the $\mathrm{CNS}^{2,3}$. In vitro studies suggest that oligodendrocyte differentiation is the constitutive pathway of development for the oligodendrocyte-type-2-astrocyte $(\mathrm{O}-2 \mathrm{~A})$ progenitor cell ${ }^{4,5}$, whereas type- 2 astrocyte differentiation depends on a specific inducing protein ${ }^{6}$. This protein is present in the developing optic nerve when type- 2 astrocytes are differentiating and can induce O-2A progenitor cells in vitro to express glial fibrillary acidic protein (GFAP) ${ }^{6}$, a marker of astrocyte differentiation ${ }^{7}$. Here we show that the type-2-astrocyte-inducing protein is similar or identical to ciliary neutrotrophic factor $(\mathrm{CNTF})^{\mathbf{8 , 9}}$, which promotes the survival of some types of peripheral neurons in vitro ${ }^{8}$, including ciliary ganglion neurons ${ }^{8,10}$. This suggests that $\mathrm{CNTF}$, in addition to its effect on neurons, may be responsible for triggering type-2 astrocyte differentiation in the developing CNS.

CNTF was purified from rat sciatic nerve using a modification of the method used previously ${ }^{9}$. When it was added to cultures of postnatal-day-0 (P0) rat optic nerve cells it induced GFAP expression in about $20 \%$ of O-2A progenitor cells (Fig. 1a). The same result was obtained with an extract of 3-4-week-old rat optic nerve (Fig. $1 b$ ), as described previously ${ }^{6}$. CNTF and optic nerve extract had the same effect when added simultaneously as when either was added alone (Fig. 1b). Two other neurotrophic factors, nerve growth factor ${ }^{1,12}$ and brain-derived growth factor ${ }^{13}$, had no effect on GFAP expression in this assay (not shown).

CNTF and the type-2-astrocyte-inducing protein share several properties. They are both acidic (ref. 9 and unpublished observations), with a relative molecular mass $\left(M_{r}\right)$ of about 25,000 (25K) (refs 6 and 9), and present at relatively high concentrations in sciatic nerve ${ }^{6,14}$ and kidney (ref. 9 and unpublished observations), compared with liver, retina or brain (refs 6,14 and unpublished observations). If the type-2-astrocyte-inducing activity in optic nerve extracts is CNTF, then these extracts should support ciliary ganglion neuron survival in vitro, which they did (Fig. 1d). The responses of both ciliary ganglion neurons and $\mathrm{O}-2 \mathrm{~A}$ progenitor cells were elicited within a similar range of concentrations (Fig. 1); the specific activity of optic nerve extract was about 1,300-fold less than that of CNTF in both assays.

When tested on optic nerve cells CNTF had many of the functional properties previously described for optic nerve extract $^{6}$. First, CNTF had no appreciable effect on GFAP expression in type-1 astrocytes or their precursors in cultures of embryonic day 17 (E17) optic nerve cells, even though it induced many of the $\mathrm{O}-2 \mathrm{~A}$ progenitor cells in such cultures to express GFAP (not shown). Second, unlike fetal calf serum (FCS), which is also an inducer of type- 2 astrocyte differenti-

$\dagger$ Present address: Department of Pharmacology, Stanford University Medical School, Stanford, California 94305, USA.
Table 1 The GFAP-inducing effect of CNTF is transient and decreases with increasing age of optic nerve

\begin{tabular}{ccccc}
\hline & & \multicolumn{3}{c}{$\%$ O-2A progenitor cells expressing GFAP } \\
\cline { 3 - 5 } Age of & Days & With CNTF & With optic \\
nerve extract & With \\
rats & in vitro & $\left(1-4 \mathrm{ng} \mathrm{m}^{-1}\right)$ & $\left(2 \mu \mathrm{gl}^{-1}\right)$ & neither \\
E18 & 1 & $35 \pm 2$ & $30 \pm 4$ & 0 \\
P0 & 1 & $21 \pm 5$ & $19 \pm 4$ & 0 \\
P7 & 1 & $9 \pm 5$ & $8 \pm 4$ & $0.2 \pm 0.5$ \\
P0 & 1 & $18 \pm 7$ & $18 \pm 5$ & 0 \\
P0 & 3 & 0 & 0 & 0 \\
\hline
\end{tabular}

Optic nerve cells were prepared, cultured, and assayed as described in Fig. 1. Results are expressed as mean \pm standard deviation of at least three cultures.

ation in vitro ${ }^{\prime}$, CNTF induced only a proportion of $\mathrm{O}-2 \mathrm{~A}$ progenitor cells in optic nerve to express GFAP, and this proportion decreased with increasing age from E18 to P7 (Table 1). Third, and again unlike FCS, CNTF caused only transient GFAP expression in O-2A progenitor cells, even when added daily: the response was maximal by 1 day and gone by 3 days (Table 1). This suggests that CNTF can initiate type-2 astrocyte differentiation but cannot on its own induce $\mathrm{O}-2 \mathrm{~A}$ progenitor cells to complete the process. Both the age-dependence and transient nature of the response are discussed elsewhere (ref. 6 and L.E.L. and M.C.R., in preparation).

The type-2-astrocyte-inducing activity in optic nerve extract co-migrated with purified CNTF on SDS-polyacrylamide gel electrophoresis (SDS-PAGE) (Fig. 2). When an extract of 3-4week-old rat optic nerve was submitted to the same purification procedure used to obtain sequence-pure CNTF from rat sciatic nerve extract, several polypeptides of $M_{\mathrm{r}} \approx 25 \mathrm{~K}$ were obtained. This semi-purified preparation from optic nerve had type-2astrocyte-inducing activity and promoted ciliary ganglion neuron survival (Fig. 3), and the specific activity was about 10-fold less than that of CNTF purified from sciatic nerve (compare Figs 1 and 3 ). Thus a protein with very similar properties to CNTF is present in optic nerve, but it could not be purified by this procedure, at least partly because it is apparently present at much lower concentrations in optic nerve than in sciatic nerve: in both type-2 astrocyte induction and neuronal survival assays, crude extracts of sciatic nerve had at least a 10-fold higher specific activity than crude extracts of optic nerve (data not shown).

We showed previously that extracts of optic nerve from 3-4week-old rats have 20 - to 100 -fold higher type-2-astrocyteinducing activity than extracts of optic nerve from 1-week-old rats, when normalized for total protein concentration ${ }^{6}$. When tested in the ciliary ganglion neuron survival assay, extracts of 3-4-week-old nerves had a half-maximal effect at around $1 \mu \mathrm{g} \mathrm{ml}^{-1}$ of total protein whereas an extract of 4-5-day-old nerves had a half-maximal effect at around $25 \mu \mathrm{g} \mathrm{ml}^{-1}$.

Taken together, our results indicate that the type-2-astrocyteinducing protein in optic nerve is CNTF or a closely related protein. Several lines of evidence suggest that this protein is responsible for timing the onset of type- 2 astrocyte differentiation. (1) It greatly increases in the optic nerve between the first and third postnatal weeks ${ }^{6}$, when type- 2 astrocytes develop in vivo $^{16}$ (2) It acts on $\mathrm{O}-2 \mathrm{~A}$ progenitor cells isolated from E17-18 optic nerve ${ }^{6}$, which is more than 10 days before these cells normally develop into type- 2 astrocytes ${ }^{16}$. This suggests that it is the increase in the CNTF-like protein rather than the onset of progenitor cell responsiveness to the protein that is responsible for timing type- 2 astrocyte differentiation in the developing optic nerve. (3) A similar molecule with type-2-astrocyteinducing activity is released by cultures of embryonic rat brain starting at the time type- 2 astrocytes begin to develop; extracts of such cultures have much more of this activity and also promote ciliary ganglion neuron survival, while extracts pre- 

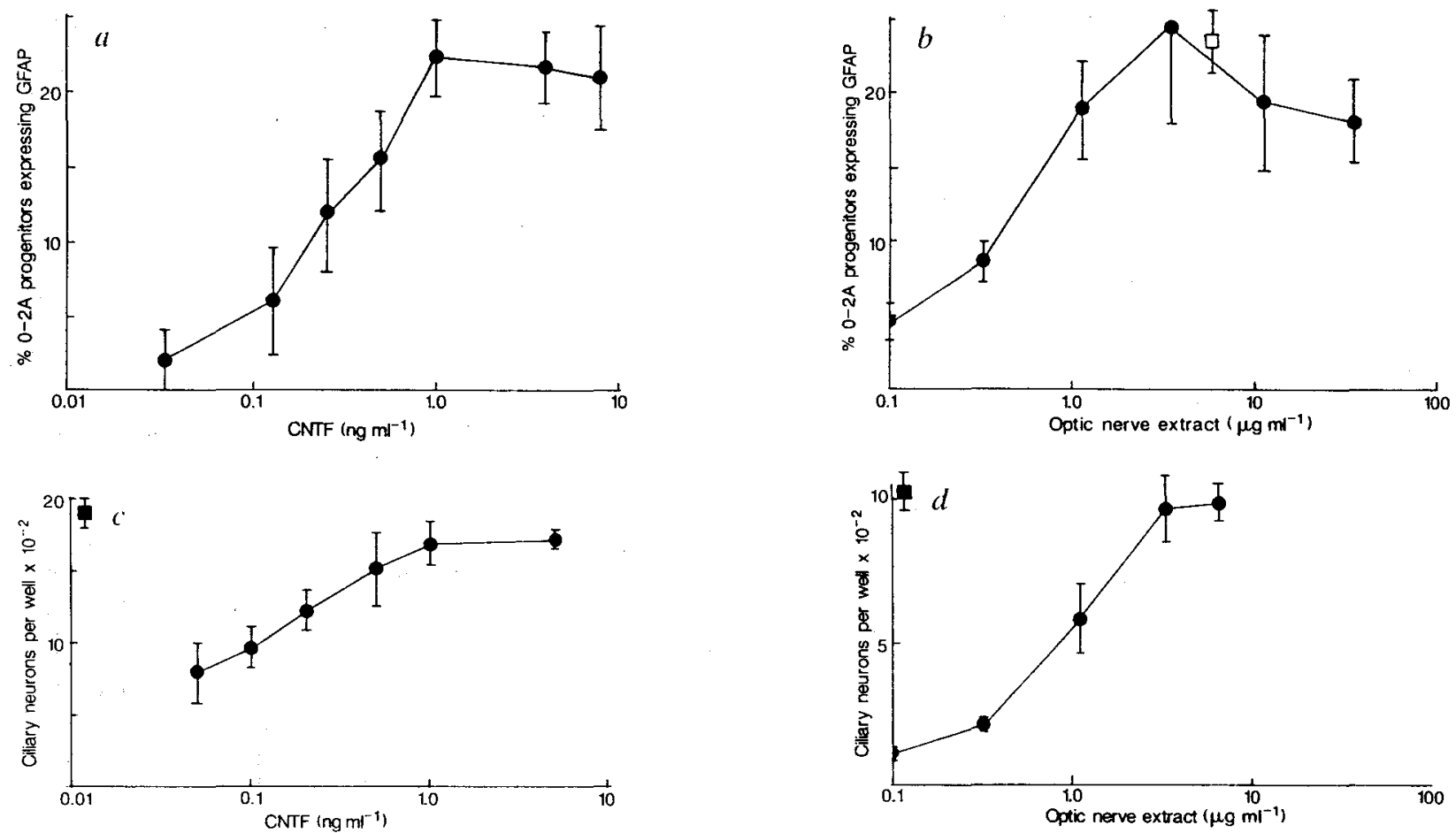

Fig. 1 The effects in vitro of sciatic nerve CNTF and optic nerve extract on GFAP expression in O-2A progenitor cells $(a$ and $b)$ and on survival of ciliary ganglion neurons $(c$ and $d)$.

Methods. Optic nerve cells from newborn (P0) Sprague-Dawley (S-D) rats were prepared as previously described ${ }^{16}$ except that the dissociation was by 10 passages through a Pasteur pipette and the cells were washed in Dulbecco's modified Eagles' medium (DMEM) containing a variety of additives (modified from Bottenstein and Sato ${ }^{24}$ as previously described ${ }^{4}$ ) and $0.5 \%$ fetal calf serum. The cells were cultured in the same medium on poly-D-lysine-coated coverslips (about 8,000 cells per coverslip) with CNTF, or optic nerve extract or both ( $\square, 5 \mathrm{ng} \mathrm{ml^{-1 }}$ of CNTF and $8 \mu \mathrm{g}^{-1}$ of extract) for $24 \mathrm{~h}$. After fixation in $4 \%$ paraformal-dehyde in phosphate-buffered saline for 5 min at room temperature, the cells were double-labelled with the A2B5 monoclonal antibody ${ }^{25}$ followed by goat anti-mouse immunoglobulin $G$ (Ig G) coupled to rhodamine (Cappel, 1:100), and then (after postixation in acid-alcohol) rabbit anti-GFAP serum ${ }^{26}(1: 1000)$ followed by sheep anti-rabbit IgG coupled to fluorescein (Wellcome, 1:100), as previously described ${ }^{\circ}$. The cells were then mounted and examined in a fluorescence microscope to determine the proportion of $\mathrm{O}-2 \mathrm{~A}$ progenitor cells (recognized by their process-bearing morphology and staining with the A2B5 antibody 1,27 ) that expressed GFAP as described previously ${ }^{6}$. Ciliary ganglion neurons were prepared from 8-day-old chick embryos and cultured at a density of $1-2 \times 10^{3}$ cells well ${ }^{-1}$ in multiwell dishes $\left(\right.$ Costar, $16 \mathrm{~mm}$ ) in F14 medium with $10 \%$ horse serum, as previously described ${ }^{28}$, except that the culture dishes were coated with laminin (BRL, $2 \mu \mathrm{g}$ in $500 \mu \mathrm{l}$ per well) instead of heart-conditioned medium. The number of neurons initially plated per well was determined by counting the neurons $2 \mathrm{~h}$ after plating (ם). After $24 \mathrm{~h}$ the number of surviving neurons was counted. Each point is the mean of at least 3 determinations (except for the two highest concentrations in Fig. $3 b$ which were done in duplicate) and the bars represent the standard errors. Extracts of optic nerves from 3-4-week-old S-D rats were prepared as previously described ${ }^{6}$. CNTF was prepared from adult Wistar rats by a modification of the method of Manthorpe and co-workers ${ }^{8,9}$, using DEAE ion-exchange chromatography and preparative SDS-PAGE. The purified CNTF gave a single silver-stained band when analysed by SDS-PAGE (see Fig. 2) or isoelectric focussing (not shown); partial amino acid sequence analysis of fragments of the purified protein has shown that the preparation contains a single protein. Both CNTF and optic nerve extract lost biological activity with freezing and thawing, which probably accounts for the small differences in the dose-response curves between $a$ and $c$ and between $b$ and $d$.

Fig. 2 The type-2-astrocyte-inducing activity in optic nerve extract co-migrates with CNTF on SDS-PAGE

Methods. CNTF and an extract from 3-4-week-old rat optic nerve were fractionated by electrophoresis on a $15 \%$ SDS polyacrylamide gel under non-reducing conditions $\mathrm{s}^{29}$, along with standard relative molecular mass markers, as previously described ${ }^{6}$. One track containing crude optic nerve extract ( $7 \mu \mathrm{g}$ of protein) and another containing $20 \mathrm{ng}$ of pure CNTF were silver-stained ${ }^{30}$ and are shown at the top of the figure. Another track from the same gel, containing crude optic nerve extract ( $100 \mu \mathrm{g}$ of protein) was cut into $2.5 \mathrm{~mm}$ slices and the protein in each slice was eluted in $0.5 \mathrm{ml}$ DMEM containing $0.5 \mathrm{mg} \mathrm{m}^{-1}$ bovine serum albumin ${ }^{31}$, as previously described $^{6}$; the protein eluted from each slice was tested (at a final dilution of $1: 10$ ) on cultures of PO optic nerve cells for GFAPinducing activity as described in Fig. 1. The arrowheads indicate the positions of standard markers (BRL), while the numbers over the arrowheads indicate the $M_{r}\left(\times 10^{-3}\right)$ of the markers.
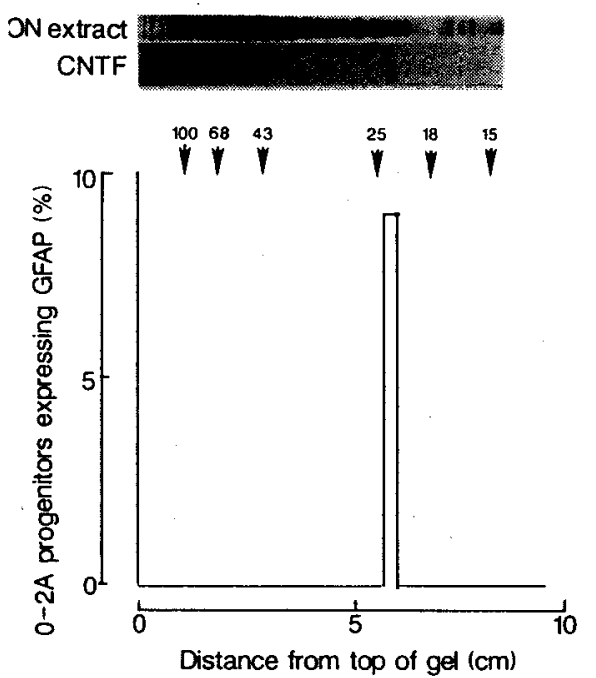

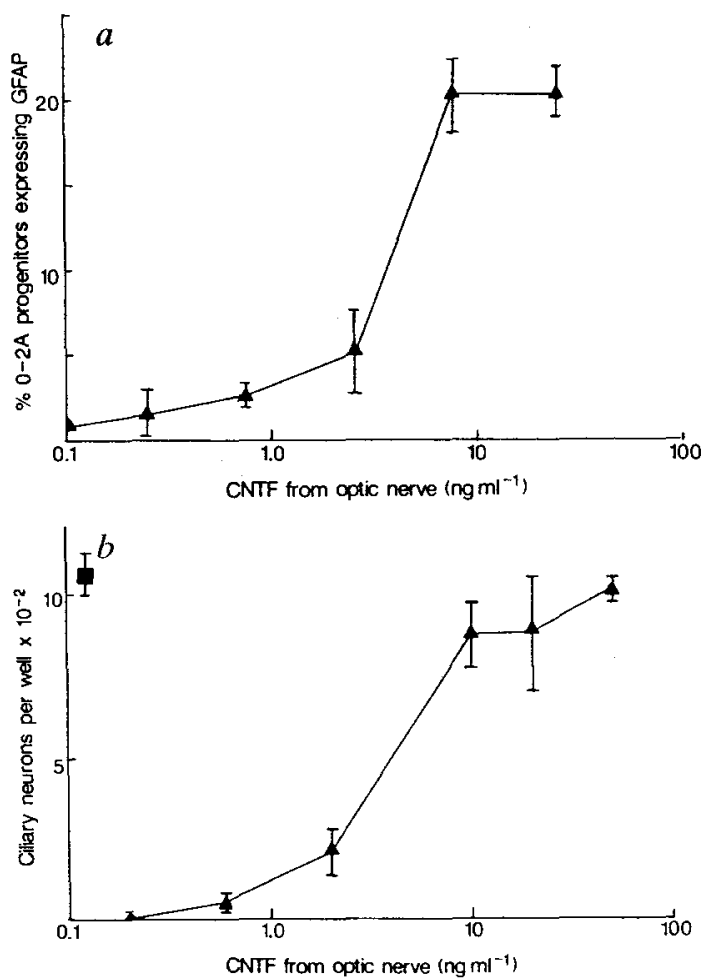

Fig. 3 The effects in vitro of CNTF prepared from optic nerve on GFAP expression in O-2A progenitor cells $(a)$ and on survival of ciliary ganglion neurons $(b)$.

Methods. CNTF was prepared from the optic nerves of 3-4-weekold S-D rats and assayed as described in Fig. 1. Optic nerve cells were prepared as described in Fig. 1 or as previously described ${ }^{4}$.

Received 20 May; accepted 13 July 1988.

1. Raff, M. C., Miller, R. \& Noble, M. Nature 303, 390-396 (1983).

2. firench-Constant, C. \& Raff, M. C. Nature 323, 335-338 (1986).

3. Miller, R. H., french-Constant, C. \& Raff, M. C. A. Rev. Neurnsci. (in the press).

4. Raff, M. C., Abney, E. R. \& Fok-Seang, J. Cell 42, 61-69 (1985).

5. Temple, S. \& Raff, M. C. Nature 313, 223-225 (1985).

6. Hughes, S. M. \& Raff, M. C. Development 101, 157-167 (1987)

7. Bignami, A., Eng, L. F., Dahl, D. \& Uyeda, C. T. Brain Res. 43, 429-435 (1972)

8. Barbin, G., Manthorpe, M. \& Varon, S. J. Neurochem. 43, 1468-1478 (1984).

9. Manthorpe, M., Skaper, S. D., Williams, L. R. \& Varon, S. Brain Res. 367, 282-286 (1986)

10. Helfand, S., Smith, G. A. \& Wessells, N. K. Devl Biol. 50, $541-547$ (1976).

11. Greene, L. A. \& Shooter, E. M. A Rev. Neurosci. 3, 353-402 (1980).

2. Levi-Montalcini, R. Science 237, 1154-1162 (1987)

3. Barde, Y.-A., Edgar, D. \& Thoenen, H. EMBO J. 1, 549-553 (1982)

14. Rudge, J. S., Davis, G. E., Manthorpe, M. \& Varon, S. Devl Brain Res. 32, $103-110$ (1987)

5. Richardson, W. D., Pringle, N., Mosley, M., Westermark, B. \& Dubois-Dalcq, M. Cell 53, 309-319 (1988).

16. Miller, R. H., David, S., Patel, R., Abney, E. R. \& Raff, M. C. Devi Biol. 111, 35-41 (1985).

17. Lillien, L. E., Sendtner, M., Rohrer, H., Hughes, S. M. \& Raff, M. C. Neuron (in the press) pared from cultures before type- 2 astrocytes have appeared have at least 50 -fold less of both activities ${ }^{17}$.

Studies on the development of optic nerve glial cells in culture have suggested that type-1 astrocytes, the first glial cells to develop in the nerve ${ }^{16}$, play a crucial role in timing the start of oligodendrocyte differentiation ${ }^{4,18}$ by secreting platelet-derived growth factor (PDGF) ${ }^{15,19,20}$. The PDGF stimulates O-2A progenitor cells to proliferate ${ }^{15,18}$ and drives an intrinsic clock in the progenitor cells that determines when they will differentiate into oligodendrocytes ${ }^{20}$. There is evidence that type-1 astrocytes in culture can also synthesize CNTF or a closely related molecule ${ }^{21}$, which can initiate differentiation along the type-2 astrocyte pathway ${ }^{17}$. Thus, by secreting PDGF and CNTF, type1 astrocytes may regulate the timing of both olidogendrocyte and type- 2 astrocyte development. The ability to reconstitute this timing in vitro ${ }^{17,22}$ should facilitate the task of determining how the synthesis (or release) of these proteins is regulated.

CNTF was originally identified ${ }^{10}$ and isolated ${ }^{8,9}$ as a factor that promotes the survival of postmitotic peripheral neurons in vitro. It has recently been shown that CNTF also affects the proliferation ${ }^{23}$ and differentiation (H.R. and U. Ernsberger, submitted) of E7 chick sympathetic neurons in vitro. These findings, together with the results presented here, suggest a role for CNTF in the control of both neuronal and glial differentiation.

We thank $\mathrm{H}$. Thoenen and Y.-A. Barde for helpful discussions, A. Mudge for helpful comments on the manuscript, and Eva Schmitz for excellent technical assistance. S.M.H. was supported by a grant from the National Fund for Research into Crippling Diseases and L.E.L. by a Fellowship from the National Multiple Sclerosis Society of the United States.

18. Noble, M. \& Murray, K. EMBO J. 3, 2243-2247 (1984).

19. Noble, M., Murray, K., Stroobant, P., Waterfield, M. \& Riddle, P. Narure 333, 559-561 (1988).

20. Raft, M. C., Lillien, L. E., Richardson, W., Burnes, J. \& Noble, M. Nature 333, 562-565 (1988).

21. Rudge, J. S., Manthorpe, M. \& Varon, S. Deul Brain Res. 19, 161-172 (1985)

22. Williams, B. P., Abney, E. R. \& Raff, M. C. Devl Biol, 112, 126-134 (1985)

23. Rohrer, H. Sendtner, M. \& Ernsberger, U. Biol. Chem. Hoppe Seyler 368, 1290-1291 (1987).

23. Rohrer, H., Sendtner, M. \& Ernsberger, U. Biol. Chem. Hoppe Seyler 368, 1290-1291 (1)
24. Bottenstein, J. E. \& Sato, G. H. Proc. natn. Acad. Sci. U.S.A. 76, 514-517 (1979).

24. Bottenstein, J. E. \& Sato, G. H. Proc. natn. Acad. Sci. U.S.A. 76, 514-517 (1979).
25. Eisenbarth, G. S., Walsh, F. S. \& Nirenberg, M. Proc natn. Acad. Sci. U.S.A. 76, 4913-4917 Eisenbarth

26. Pruss, R. Nature 280, 688-690 (1979).

27. Temple, S. \& Raff, M. C. Cell 44, $773-779$ (1986)

28. Harper, G. P. et al. Neuroscience 8, 375-387 (1983)

29. Laemmli, U. K. \& Favre, M. J. molec Biol. 80, 577-599 (1974)

30. Oakley, B. R., Kirsch, D. R. \& Morris, N. R. Analyt. Biochem. 105, 361-363 (1980).

31. Lemke, G. E. \& Brockes, J. P. J. Neurosci. 4, 75-83 (1984) 